\title{
ADOLESCENTES E GRÁVIDAS: ONDE BUSCAM APOIO?
}

\author{
Roseli Aparecida Godinho* \\ Joselaine Rosália Batista Schelp* \\ Cristina Maria Garcia de Lima Parada** \\ Neide Marina Feijó Bertoncello**
}

GODINHO, R.A.; SCHELP, J.R.B.; PARADA, C.M.G.L.; BERTONCELLO, N.M.F. Adolescentes e grávidas: onde buscam apoio?. Rev.latino-am.enfermagem, Ribeirão Preto, v. 8, n. 2, p. 25-32, abril 2000.

Adolescência é época de crise, mudança, readaptação ao novo corpo e de novas atitudes frente a vida. Se somarmos a isso o significado da gravidez, dos pontos de vista pessoal, social e familiar, compreenderemos como a gestação pode ser um evento dificil para a adolescente. O presente estudo teve como objetivo identificar onde as adolescentes grávidas buscam apoio. Evidenciou-se que as entrevistadas puderam contar com o apoio da família, principalmente dos pais e, com menos freqüencia com o do pai do bebê, bem como a aceitação da gravidez, sua relação com o abandono escolar, a visão idealizada dessas garotas acerca da gestação e expectativas futuras, a preocupação com aspectos biológicos e a despreocupação com problemas concretos.

UNITERMOS: adolescência, gravidez na adolescência

\section{INTRODUÇÃO}

Ao se trabalhar com adolescentes é importante considerar, primeiro, o que significa esta fase, época de crise, mudança, readaptação ao novo corpo e de novas atitudes frente a vida. Se somarmos a isso o significado de uma gravidez, dos pontos de vista pessoal, social e familiar, compreenderemos como a gestação pode ser um evento difícil na vida da adolescente que, com certeza, precisa de ajuda para superar tais dificuldades.

Adolescente é todo indivíduo que estiver entre a faixa etária de 10 a 19 anos de idade segundo a ORGANIZAÇÃO MUNDIAL DE SAÚDE ${ }^{19}$. Nesse período, ocorre transição da infância para a fase adulta, além de rápidas transformações, tanto físicas e fisiológicas - crescimento acelerado, na mulher observase alargamento dos quadris e maior deposição de gordura, aparecimento de pelos pubianos e axilares, desenvolvimento mamário, menarca e início dos ciclos ovulatórios, com conseqüente capacidade reprodutiva $^{1,7,15,16,23}$, quanto psicossociais - conflito com o início das relações sexuais, momentos de incerteza, ansiedade, insegurança, isolamento, transtornos de vínculos afetivos, consolidação da auto-imagem e autoestima, amadurecimento emocional e mental, questionamento sobre imposições, regras, valores, identidade, conflitos familiares, emocionais e sociais, com preocupação quanto à formação de grupos de amigos $1,7,8,14,16,22$.

Durante esse período de transformações o apoio dado às adolescentes é muito importante, para que essas tolerem as mudanças a que estão sujeitas e não se sintam vulneráveis às mudanças biopsicossociais. Para tanto, a família deve estar bem estruturada, a fim de não facilitar a ocorrência, comum entre as adolescentes, de violência, uso de drogas e gravidez precoce ${ }^{13}$.

$\mathrm{Na}$ adolescência, o indivíduo ainda não possui capacidade para racionalizar as conseqüências futuras, decorrente do seu comportamento sexual, deparando-se freqüentemente com situações de risco, como gravidez não planejada ou desejada ${ }^{6}$.

Nesta época acontecem modificações da sexualidade que, se associada a falta de apoio familiar e de expectativas de vida, levam a perda da auto-estima e baixo rendimento escolar. Além disso, a falta de lazer, maus exemplos familiares, curiosidade natural, necessidade de expressar amor e confiança, solidão, carência afetiva e necessidade de afirmação, são também elementos que podem levar a adolescente a iniciar sua vida sexual precocemente, com risco de uma gravidez indesejada ${ }^{4,6}$. Ao mesmo tempo, surge entre as adolescentes o interesse de quebrar tabus de cunho moral, impostos pela sociedade, levando as jovens a contestar, mantendo relações sexuais ilícitas, na busca da libertação da tutela paterna ${ }^{4,8,21}$.

\footnotetext{
* Aluna do Curso de Graduação em Enfermagem da Faculdade de Medicina de Botucatu-UNESP

** Enfermeira. Professor Assistente Doutor do Curso de Enfermagem da Faculdade de Medicina de Botucatu-UNESP
} 
Ainda outros fatores podem favorecer a ocorrência de uma gravidez indesejada, como: ausência de educação sexual nas escolas e de programas de planejamento familiar nos serviços públicos de saúde ${ }^{8,10,12,20}$. As adolescentes grávidas estão inseridas num contexto de conflitos: criança ou mulher, filha ou mãe, não sabendo se comportar diante da gravidez e sem saber que atitude adotar diante da sociedade e consigo mesma $^{3,7,9}$

Do ponto de vista obstétrico, a gravidez na adolescência é considerada de alto-risco, devido ao elevado índice de morbidade materno-fetal. Existe maior incidência de anemia, toxemias (pré-eclâmpsia e eclâmpsia), infecção urinária, baixo ganho de peso materno, prematuridade, baixo peso ao nascer, baixo índice de Apgar e desmame precoce, além de baixa cobertura pré-natal ${ }^{2,5,20,22}$.

A gravidez traz vários efeitos sociais negativos, como: perda das oportunidades educacionais, de trabalho e redução das chances de um casamento feliz, com limitações de oportunidade ${ }^{8,10}$. Ocorrem também efeitos psicológicos associados ao conflito emocional e educacional frente a situação da maternidade $\mathrm{e}^{10,22}$.

Percebe-se, também, a falta de apoio, despreparo ou abandono por parte do parceiro, causando a interrupção do processo normal do desenvolvimento psico-afetivo-social: na maioria dos casos a gestante não tem nem vínculo com o parceiro, nem o apoio da família ${ }^{6}$. Ao contrário, freqüentemente sofrem críticas de familiares, seja pelas pressões sociais envolvidas, seja por problemas financeiros. Ademais, muitas vezes, não podem contar com o apoio de amigos ou vizinhos, sentemse envergonhadas, culpadas e têm dúvidas quanto ao seu futuro e ao de seu filho ${ }^{8}$.

Quando as adolescentes percebem que estão grávidas, elas recorrem, primeiramente, ao parceiro, depois a sua mãe e em seguida aos amigos, sendo que, habitualmente, a comunicação pode ser melhor estabelecida com a mãe ${ }^{13}$.

As dificuldades encontradas pelas adolescentes são diferentes, dependendo de sua classe social. Entre as de baixa renda, há famílias que acolhem melhor, com apoio essencial, podendo as adolescentes continuar os estudos e/ou trabalhar. Por outro lado, os pais podem rejeitá-las e/ou abandoná-las, restando a elas, muitas vezes, a prostituição. Já em classes sociais de renda mais alta a adolescente tem, geralmente, como alternativas o casamento ou o aborto ${ }^{10}$. Independentemente da classe, porém, o sentimento de culpa da gestante acarreta conflitos inconscientes, gerados pela desobediência das leis sociais, com reflexo na aceitação do filho ${ }^{13}$. Após o parto, a adolescente questiona o significado da criança em sua vida e defronta-se com a falta de condições econômicas para criá-la ${ }^{3}$.
Pelo exposto, fica claro que as adolescentes grávidas necessitam de atenção especializada e, para tanto, têm sido criados programas de assitência pré-natal específicos para este grupo, os quais buscam, através de uma equipe multidisciplinar, implementar uma assistência pré-natal integral e incrementar a auto-estima, fundamental quando se pretende formar uma família e oferecer amparo, com tolerância e flexibilidade, diminuindo, assim, a ansiedade da gestante, o que favorece e consolida seu papel de mãe ${ }^{22}$. Entretanto, muitas adolescentes não têm tido acesso a esses programas, ainda escassos no país ${ }^{18}$.

Se a família muitas vezes a rejeita, o parceiro a abandona, os serviços de saúde especializados são ainda insuficientes e a escola não está preparada para auxiliála, onde as adolescentes têm buscado ajuda? O presente estudo tem por objetivo identificar onde as adolescentes grávidas têm buscado apoio para enfrentar sua gravidez.

\section{ASPECTOS METODOLÓGICOS}

\subsection{Local de realização do estudo}

Fizemos a opção de realizarmos este estudo no Hospital das Clínicas da Faculdade de Medicina de Botucatu-UNESP, porque este possui um serviço pré-natal destinado exclusivamente às gestantes adolescentes, que acabam dando a luz nele. Tal hospital tem capacidade de 28 leitos de obstetrícia, dos quais 12 são destinados ao alojamento conjunto, 3 ao isolamento e 13 a gestantes patológicas e puérperas. Possui, também, 3 leitos para pré-parto.

\subsection{Referencial teórico}

Se pretendemos estudar as fontes de apoio das jovens gestantes, não podemos esquecer de sua determinação sócio-cultural, daí a necessidade de buscar contextualizar, relacionar e conhecer as contradições da gravidez na adolescência, entendendo a adolescente como sujeito de sua realidade.

Considerando o fenômeno estudado desta perspectiva, pareceu-nos apropriado utilizar uma metodologia de cunho qualitativo, buscando o significado que as pessoas dão às coisas e aos fatos de sua vida, $o$ que vem ao encontro do nosso objetivo, que é o de obter dos próprios sujeitos da pesquisa o entendimento que possuem do fenômeno a ser estudado ${ }^{17}$.

Outro aspecto importante a ser ressaltado é que esta linha de pesquisa facilita o estudo de um fenômeno contemporâneo da vida real, contextualizando-o, possibilitando sua compreensão, levando em consideração as ações, percepções, comportamentos e 
interações dos indivíduos com o problema em questão, no nosso caso, a adolescente grávida e sua fonte de apoio. Além disso, permite usar dados de níveis abstratos, subjetivos, que auxiliam na visão mais integral do indivíduo.

Buscando conhecer, na perspectiva da própria adolescente, quem as têm apoiado, entrevistamos 20 puérperas com idade igual ou inferior a 19 anos, que deram a luz no Hospital das Clínicas da Faculdade de Medicina de Botucatu, independente de sua paridade. Este número de entrevistas se mostrou suficiente para o esclarecimento e entendimento acerca do problema em questão. Ressaltamos que no período estudado 516 mulheres deram a luz no Hospital das Clínicas e, destas, $44(8,5 \%)$ tinham idade igual ou inferior a 16 anos e 92 $(17,8 \%)$ estavam na faixa etária entre 17 e 19 anos, totalizando $26,3 \%$ de partos em adolescentes.

\subsection{Coleta e análise de dados}

A realização deste estudo obteve aprovação do Comitê de Ética em Pesquisa da Faculdade de Medicina de Botucatu e os dados foram colhidos no período entre abril e setembro de 1998, na Enfermaria de Obstetrícia do Hospital das Clínicas da mesma Faculdade, através de entrevista semi-estruturada, gravada após a permissão da puérpera. O roteiro utilizado contava com uma parte que objetivava caracterizar a adolescente no seu contexto sócio-cultural, uma segunda que buscava dados ginecológicos e outra parte que continha questões relacionadas aos seus sentimentos frente a gravidez. Este último bloco de questões foi o foco do nosso estudo, porém sempre buscando sua relação e contradições com os demais.

Após as entrevistas, as fitas gravadas foram transcritas na íntegra e, a seguir, realizamos a leitura exaustiva, repetida e atenta das informações obtidas, a fim de estabelecermos classificações, agrupando elementos ou aspectos com características comuns ou que mantinham relação entre si, a que passamos chamar de categorias. Para GOMES ${ }^{11}$, trabalhar com categorias significa agrupar elementos, idéias ou expressões em torno de um conceito capaz de abranger tudo isso. Antes, porém, de efetuarmos a categorização mencionada, realizamos uma descrição acerca do perfil social das adolescentes.

\section{RESULTADOS E DISCUSSÃO}

\subsection{O perfil social das adolescentes}

A idade das adolescentes variou de 13 a 19 anos, sendo que metade delas tinha até 16 anos e, muito embora se questione a definição de adolescência através da idade cronológica, pois trata-se de época de inúmeras transformações e influenciada por fatores culturais, sociais e econômicos, ainda hoje a definição que prevalece é baseada na idade. Deve-se ponderar, entretanto, que a faixa etária de 10 a 19 anos é ampla, sendo bastante diferente considerar a ocorrência de uma gravidez em uma jovem de 13 ou outra de 19 anos. Assim, eventualmente, apresentaremos os dados de acordo com as seguintes faixas etárias: menor ou igual a 16 anos e entre 17 e 19 anos.

Quanto a procedência, 8 adolescentes $(40,0 \%)$ eram do município de Botucatu e as demais eram de cidades vizinhas. Indagadas acerca da situação marital, apenas 4 entrevistadas $(20,0 \%)$ disserem ser legalmente casadas; outras $10(50,0 \%)$, embora solteiras, moravam com o companheiro; 1 estava solteira, mas namorando o pai do bebê e $5(25,0 \%)$ estavam solteiras e sem companheiro.

As 5 adolescentes solteiras e sem companheiro e aquela que mantinha o namoro com o pai de seu filho, moravam com os pais e irmãos. Destacamos que destas 6 garotas, 5 tinham idade igual ou inferior a 16 anos. Este fato corrobora a idéia de que alguns problemas das adolescentes mais jovens são específicos, apontado para a necessidade de, em alguns momentos, realizarmos a análise de acordo com a idade das adolescentes, como mencionamos anteriormente. As demais moravam com o marido ou companheiro, sendo que 2 delas na casa dos pais e 3 na casa do sogro. Entre aquelas que estavam totalmente sozinhas, as razões citadas para a separação foram: "a gente não dá certo", "ele não me ama", "eu não quero mais" ou simplesmente "a gente se separou". Foram apresentadas razões superficiais, sem reflexão e implicações para vida dos envolvidos.

Observamos, então, uma relação direta entre a instabilidade da relação e a idade, de forma que quanto mais jovem a garota, mais instável, o que se traduz pelo fim da relação ainda durante a gravidez e manutenção da residência com os pais. Quanto aos motivos disso, transparece a visão romântica e idealizada dessas adolescentes, quando dizem "ele não me ama e o tanto que eu gosto dele não foi suficiente" ou "a gente se separou, mas talvez a gente ainda volte". Esse fato, reporta-nos a refletir sobre os motivos que levaram à gravidez e se entre eles estava o de independência dos pais, nosso estudo concorda com aqueles que apontam para a frustração desse desejo entre as adolescentes.

A pergunta acerca da renda familiar foi a que as adolescentes mais hesitaram em responder, sendo que 7 delas disseram não a conhecer. Entre aquelas que responderam, mais da metade referiu uma renda mensal familiar inferior a 3 salários mínimos, o que mostra tratar- 
se de um grupo com baixo poder aquisitivo. $\mathrm{O}$ fato das adolescentes desconhecerem a renda familiar reflete o pouco envolvimento com a realidade concreta de seu sustento e de seu filho, mostrando mais uma vez que a gravidez não foi conscientemente programada ou o foi de forma idealizada.

Com relação a pessoa que tem desempenhado o papel de arrimo de família, $11(55,0 \%)$ citaram o marido, sendo que 1 deles estava desempregado e $7(35,0 \%)$ citaram os pais e, entre estas, 5 tinham idade igual ou inferior a 16 anos; também neste grupo havia 1 desempregado. Quanto a profissão do arrimo de família apresentada pelas entrevistadas, o destaque foi para os trabalhadores rurais ( 5 casos, $25,0 \%$ ).

A escolaridade das adolescentes era, em geral, abaixo daquela esperada para a idade. Mesmo considerando que 2 tinham até 14 anos e que, para elas, ainda que não tivesse ocorrido repetência o primeiro grau poderia não estar concluído, podemos afirmar ser a escolaridade baixa, pois apenas 2 delas tinham completado o $1^{\circ}$ grau e 1 o $2^{\circ}$ grau.

A situação escolar ficou mais clara quando indagamos sobre a condição atual, sendo que apenas 1 das adolescentes ainda estava freqüentando a escola. Ressaltamos que as entrevistas foram realizadas após o parto, a gravidez foi a causa do abandono escolar para 9 adolescentes $(47,4 \%)$ e, destas, 6 tinham idade igual ou inferior a 16 anos. Quanto as outras 10 adolescentes, 1 havia parado de estudar após ter concluído o segundo grau e as outras 9 abandonaram o estudo antes mesmo de saberem que estavam grávidas.

O expressivo número de adolescentes que abandonaram os estudos devido a gravidez, pode ter relação com a vergonha destas meninas mais jovens em assumirem-na, de enfrentarem os colegas e professores, pois estão muitas vezes sozinhas. A saída mais fácil acaba sendo o abandono escolar já no início da gravidez, o que pode ser evidenciado através de justificativas como: "parei de estudar porque estava grávida, porque achei chato continuar" ou mesmo " parei de estudar por causa da gravidez, na escola falaram que foi besteira minha ter feito isso". Esses depoimentos fazem-nos pensar, também, em como a escola pode estar se comportando frente ao problema da gravidez na adolescência: omissão quanto aos aspectos educativos/preventivos e preconceito após o fato consumado.

Estes dados reforçam as discussões que têm sido realizadas acerca dos problemas sociais da mãe adolescente. Essas garotas, com baixa escolaridade, têm menor chance frente a um mercado de trabalho cada vez mais competitivo e, mesmo quando conseguem colocação, isso se dá em atividades com baixa remuneração, o que as mantém, freqüentemente, dependentes dos familiares ou companheiro. Destacamos, porém, que nenhuma adolescente referiu ter trabalhado durante a gravidez.

Essas características sociais das adolescentes entrevistadas são compatíveis com a clientela habitual do hospital em que o estudo foi realizado, pois trata-se de um hospital universitário, cujas internações ocorrem através do Sistema Unificado de Saúde. Além disso, é sabido que as pessoas com maior poder aquisitivo buscam atendimento particular ou através de convênios e de seguros- saúde.

\subsection{A iniciação sexual: precocidade}

A avaliação dos dados acerca da iniciação sexual das entrevistadas mostrou-nos uma idade média quando da primeira relação sexual de 14,7 anos e da menarca 12,3 anos. Para mais de dois terços das jovens, o tempo entre a menarca e a primeira relação sexual foi igual ou inferior a 2 anos e entre as primíparas, mais da metade delas havia namorado por um tempo igual ou inferior a 6 meses antes da gravidez.

Quanto ao recebimento de alguma orientação antes da iniciação sexual, apenas 6 adolescentes referiram que haviam tido, apresentando como fonte de informação as amigas, serviços de saúde e escola; com menos freqüência foram citados os pais e outros familiares. Embora seja apontada a necessidade de programas de orientação sexual para os adolescentes, quer para a prevenção de doenças sexualmente transmissíveis, quer para o planejamento familiar, este estudo mostrou que as entrevistadas não tiveram acesso suficiente a programas deste tipo, o que nos leva a outras questões: os programas educativos existem? estão atingido a população alvo? eles são o caminho para evitar uma vida sexual e uma gravidez precoce? Por outro lado, conforme apresentamos anteriormente, a ausência de educação sexual nas escolas e de programas de planejamento familiar nos serviços públicos de saúde, têm sido apontados como fatores que podem favorecer a ocorrência de gravidez indesejada $^{8,10,12,20}$.

Entre as 20 entrevistadas, $18(90,0 \%)$ tinham dado a luz pela primeira vez. Quanto as 2 que já tinham filhos, ambas tinham 19 anos e eram amasiadas, sendo que uma tinha 1 filho anterior, com 3 anos e a outra tinha 2 filhos, o mais velho com quatro anos e o mais jovem com 1 ano e 7 meses. Ressaltamos que entre aquelas que já tinham filho(s), todos eles eram do mesmo e atual companheiro.

É importante discutirmos que, apesar de muito freqüente, nem sempre a gravidez na adolescência é um evento único, fortuito, que "escapou" ao controle, visto que para algumas jovens isso acaba se repetindo. Entretanto, pior que uma gravidez na adolescência é sua repetição, que pressupõe problemas como o pequeno 
intervalo interpartal e maior possibilidade de baixo peso ao nascer para o bebê, além de problemas como a sobrecarga imposta a essas garotas, que têm que cuidar de 2 ou 3 filhos e, muitas vezes, da casa e do companheiro.

\subsection{Sentimentos frente a gravidez: contradição}

Os sentimentos relativos a gravidez também foram pesquisados. Dentre as entrevistadas, quase a metade delas disse que queria engravidar. Indagadas quanto ao porquê, justificaram pelo desejo de ter um filho e por gostarem de criança. Mais uma vez ao falarem de seus sentimentos, elas expressaram baixo envolvimento com a realidade, o que é compatível com suas idades, mas certamente uma gravidez precoce forçará, de alguma forma, a antecipação desse envolvimento.

Frente a notícia da gravidez, 13 adolescentes referiram terem se sentido felizes, muito embora 1 delas tenha se mostrado contraditória, ao dizer "fiquei feliz, fazer o que, né?". Entre as que manifestaram sentimentos negativos, destacam-se aquelas que responderam terem se sentido nervosas ou péssimas.

Com relação a posição do parceiro frente a gravidez, três quartos das entrevistadas disseram que eles a desejavam. Repete-se aqui, com freqüência, as mesmas razões apontadas para justificarem a vontade delas próprias terem filho, ou seja, "porque queria ter um filho" e "porque ele gosta de criança". Outros motivos citados foram: "para podermos morar juntos" e "para tentar um filho homem”. Justificativas não muito claras também foram apresentadas, como "ele aceitou bem" ou "ele ficou comigo", o que nos parece evidenciar não o desejo de gravidez da companheira, mas sim a mera resignação frente a um fato consumado. Mais uma vez a idealização dessas adolescentes transparece, ao interpretar isso como aprovação ou desejo acerca da gravidez.

Quanto as garotas que disseram que os companheiros não queriam a gravidez, os motivos apresentados foram: "porque a gravidez foi sem querer" , "ele acha que não é dele", "ele não gosta de mim" e "ele fala besteiras para mim". Estas frases mostram a imaturidade da relação, visto que muitas vezes o pai também é adolescente e incapaz de assumir o fato de que terá um filho. Nessa situação, o apoio de que trata esse estudo seria necessário não só para a gestante adolescente, mas também para o pai.

Assim, tanto as justificativas para sua própria vontade de engravidar, quanto acerca do desejo do parceiro são, na grande maioria das vezes, frágeis. Afinal, será que gostar de criança, por exemplo, é razão suficiente para engravidar na adolescência? A vontade de ter um filho nesta fase da vida, não teria relação, por exemplo, com o desejo de sentir-se mais mulher, de prender o namorado, de sair da escola ou da casa dos pais, de dar mais sentido a uma vida vazia? Entretanto, tudo isso é pensado no plano do ideal e o real começa a aflorar para essas jovens quando elas contam para o companheiro e família, podendo experimentar, então, o abandono ou uma mudança radical em suas vidas, expressa nas falas: "precisei mudar tudo na minha vida, tive que sair da escola, parar de trabalhá, tive que amigá" ou "com a gravidez tudo na vida muda".

A maior parte das entrevistadas, porém, não relatou mudança em suas vidas após a gravidez, algumas demonstrando, inclusive, que não tinham qualquer plano de vida, o que se expressou na fala: " eu não mudei nada na minha vida, eu não tinha plano nenhum”. Entre aquelas que referiram mudanças, a principal foi o abandono da escola, apontado com maior freqüência pelas adolescentes mais jovens. Ressaltamos que a perda das oportunidades educacionais tem sido apontada como um dos principais efeitos sociais negativos relacionado à gravidez na adolescência ${ }^{8,10}$.

\subsection{Gravidez: preocupação com aspectos biológicos}

O desenvolvimento da gravidez também foi investigado. Iniciamos ressaltando que todas as adolescentes referiram terem feito pré-natal, mais de dois terços, inclusive, teve 6 consultas ou mais, conforme tem sido preconizado para se considerar o acompanhamento pré-natal efetivo.

Intercorrências nesta gestação foram apontadas por 12 entrevistadas, com destaque para a infecção do trato urinário, cuja ocorrência é freqüente na gravidez, independentemente da idade da mãe. Outros problemas citados foram: doença hipertensiva específica da gravidez, trabalho de parto prematuro, oligoâmnio, cólica renal, ameaça de abortamento e perda de um gemelar, com bom termo para o segundo gêmeo.

Dentre as entrevistadas, quase metade delas não manifestou qualquer preocupação durante a gravidez. Aquelas que disseram terem se sentido preocupadas, apresentaram como causas o medo da criança não nascer bem, medo do parto, medo de abortar e medo de dar o primeiro banho.

Assim, fica claro que as adolescentes estudadas preocupavam-se com os aspectos físicos/ biológicos da gravidez: freqüentaram o pré-natal assiduamente e souberam relatar com detalhes as intercorrências apresentadas. Além disso, todas as preocupações, manifestadas por elas através do medo, também relacionavam-se apenas com o biológico. Não foram citadas, por exemplo, preocupações com trabalho, dinheiro, casa, educação ou realização pessoal, o que mais uma vez mostra um certo distanciamento da realidade concreta do dia-a-dia. 


\subsection{O importante apoio da família}

Onde as adolescentes buscam apoio? Essa era a principal resposta que buscávamos. Indagamos a respeito do apoio durante a gravidez dado pelo companheiro, pais e outros familiares, escola e serviços de saúde.

Com relação ao companheiro, 16 adolescentes disseram que eles as apoiaram. O tipo de apoio recebido variou desde aqueles que ofereceram todo tipo de ajuda até outros que auxiliaram com dinheiro, comprando roupinhas e remédios e aqueles que deram conforto e carinho. Vale ressaltar que o fato do pai do bebê assumir a criança foi também citado como apoio. A resignação destas jovens fica, então, clara. Elas não partem do princípio que é dever do pai assumir o filho e, inclusive aquelas que estavam totalmente sozinhas, em nenhum momento cobraram algo do ex-companheiro. A gravidez é tratada como um "problema" só delas. Muitas vezes, contrapõe-se a situação idealizada de uma gravidez por amor, com a realidade do abandono. Resta-lhes, entretanto, o apoio da família.

A maior parte das adolescentes (17 delas ou $85,0 \%$ ) disse ter recebido apoio da família na gravidez. Quando indagadas acerca de qual o membro da família o ofereceu, referiram pai e/ou mãe (7 vezes) e pais e outros familiares (10 vezes). Assim, embora algumas vezes outros membros da família tenham auxiliado, isso nunca ocorreu independentemente dos pais, especialmente a mãe. Estes dados estão de acordo com o estudo de GRIFFITHS et al. ${ }^{13}$, quando apontam que as adolescentes grávidas recorrem, primeiramente, ao parceiro e, em seguida, à mãe e amigos, sendo que, geralmente, a comunicação é melhor estabelecida com a mãe.

Quanto ao tipo de apoio recebido, destacamos: "explicaram coisas e deram conselhos" e "todo tipo de ajuda". A presença da mãe foi marcante, tanto positiva como negativamente. Assim, uma adolescente referiu. " no começo ela (a mãe) dizia que não era neto dela" e outra disse "ela (a mãe) sempre me acompanhava no pré-natal”.

As orientações fornecidas pelo serviço de saúde, acerca dos cuidados com o bebê ou uso de medicações, por exemplo, foram interpretadas como uma forma de apoio durante a gravidez. Quanto ao papel da escola, não pudemos avaliar, visto que apenas 1 adolescente não havia abandonado os estudos.

Conforme colocado anteriormente, algumas adolescentes abandonaram a escola antes mesmo que se pudesse perceber a gravidez. Outras, entretanto, largaram a escola por sentirem-se criticadas.

Apesar de, num primeiro momento, termos perguntado especificamente sobre o apoio do companheiro, família, escola e serviço de saúde durante a gravidez, em seguida deixamos que a gestante, espontaneamente, apontasse quem a estava apoiando naquele momento. Ou seja, após o nascimento do bebê, com quem elas estavam podendo contar? Nesta nova situação, praticamente todas elas disseram estar recebendo algum tipo de apoio, com destaque para a família, citada 16 vezes.

Quanto ao tipo de apoio recebido, ressaltamos "todo tipo de ajuda", "carinho", "apoio moral" ou, então, ajuda financeira, manifesta através de "eles (os familiares) me trazem coisas" ou " roupinhas eles (os pais) compraram". Aqui, os pais aparecem de forma importante: "falam (os pais) para não fazer mais essas coisas, entendeu? Tem pais que expulsam você de casa quando fica grávida, né. Meus pais são completamente diferentes, aceitaram numa boa" ou mesmo "ela (a mãe) tem cuidado da gente, disse que vai ajudar a cuidar do meu filho" e "eles (os pais) tão ajudando eu, assim, cuidando de mim".

\subsection{Expectativas futuras}

Quando indagadas quanto às preocupações naquele momento, as respostas mostraram, em geral, preocupações imediatas, relativas à saúde do bebê e do seu cuidado e sair logo do hospital. Muitas adolescentes, entretanto, disseram não ter qualquer preocupação.

É importante ressaltarmos que 5 adolescentes referiram não ter intenção de manter o relacionamento com o pai do bebê e, destas, 4 tinham idade igual ou inferior a 16 anos.

Expectativas futuras: quando perguntamos às adolescentes o que elas esperavam da vida, as principais respostas foram saúde, felicidade e desejo de cuidarem bem dos bebês. Entre as mais velhas, as respostas foram mais objetivas, aparecendo a intenção de voltar a estudar e trabalhar: "espero que ele (o bebê) cresça logo né, e eu volte a trabalhar pra arrumar minha casa direito" ou "espero um monte de coisa, voltar a estudar e a trabalhar para sustentar meu filho".

\section{CONSIDERAÇÕES FINAIS}

Este estudo evidenciou que, frente a gravidez, as adolescentes entrevistadas puderam contar com o apoio da família, especialmente dos pais. Este apoio foi mais evidente quanto mais jovem as garotas, pois estas geralmente tinham uma relação mais instável com o pai do bebê, não podendo, muitas vezes, contar com o apoio deles. Com menos freqüência foi citado o apoio dado pelo pai do bebê. Assim, para o grupo estudado, a gravidez acarretou maior dependência de seus pais, frustrando o desejo comum de independência e liberdade, visto que a 
maior parte das entrevistadas residiam com os pais ou sogros.

Evidenciou, também, a freqüente relação entre gravidez e abandono escolar, apontado para um possível agravamento das condições sócio-econômicas dessas adolescentes, que terão limitadas suas possibilidades de ocupação e sustento, de si e de seus filhos.

Ao contrário de muitos estudos, pudemos identificar a preocupação das adolescentes com os aspectos biológicos: o acompanhamento pré-natal foi, em geral, realizado de maneira assídua e com início precoce. Entretanto, os Serviços de Saúde e a Escola foram poucas vezes apontados como "orientadores", sugerindo que essas instituições não estão cumprindo a contento seu papel social frente às questões dessa natureza, merecendo uma revisão e construção de políticas norteadoras, que impactem na melhoria da assistência à saúde e formação escolar.

Este estudo mostrou, ainda, que apesar de, na maior parte das vezes, a gestação não ter sido planejada, esta foi aceita. A visão idealizada dessas garotas acerca da gravidez e a ausência de preocupação com problemas concretos do dia-a-dia, incluindo seu sustento, estudo, trabalho, realização pessoal e outros ficou clara. Por fim, ficou evidente a forma também idealizada com que falam de suas expectativas futuras, especialmente as mais jovens, não apresentando alternativas concretas e não visualizando caminhos promissores na sociedade em que estão inseridas.

\section{PREGNANT ADOLESCENTS: WHERE DO THEY LOOK FOR SUPPORT?}

Adolescence is the age of crises, changes, adaptation to the new body and new attitudes towards life. If we add to this the meaning of pregnancy from personal, social and family points of view, we will understand how difficult it can be for the adolescents. The purpose of this study was to identify where the pregnant teenagers look for support. Results showed that they had family support, mainly from parents, and less frequently from the baby's father. It also showed the pregnancy acceptance, its retation to school abandonment, the girls' idealized vision of pregnancy and future expectations, the concern about biological aspects and the lack of concern about real problems.

KEY WORDS: adolescence, pregnancy in adolescence

\section{ADOLESCENTES EMBARAZADAS: DONDE BUSCAN APOYO?}

La Adolescencia es una época de crisis, cambio, adaptación al nuevo cuerpo y de nuevos comportamientos frente a la vida. Si sumamos a esto el significado del embarazo, con sus aspectos personales, sociales y familiares, comprenderemos como el embarazo puede ser un evento dificil para la adolescente. Este trabajo tuvo como objetivo identificar donde las adolescentes embarazadas buscan apoyo. Evidenció que las entrevistadas tuvieron el apoyo de la familia, principalmente de los padres y con menor frecuencia el apoyo del padre de su bebé, así como la aceptación del embarazo, su relación con el abandono escolar, la visón idealizada de esas jóvenes acerca del embarazo y futuras expectativas, la preocupación con aspectos biológicos y la despreocupación con problemas concretos.

TÉRMINOS CLAVES: adolescencia, embarazo en la adolescencia

\section{REFERÊNCIAS BIBLIOGRÁFICAS}

01. ANDRADE, H.H.S.M. et al. Atendimento ambulatorial informatizado de adolescentes. J. Pediatr., v. 72, n. 5, p. 319-23, 1996.

02. BERKOW, R. et al. Manual merk de medicina. 15. ed. São Paulo: Rocca, 1989. p. 2341-53.

03. BIO, E.R. et al. Gestação na adolescência: aspectos somatopsíquicos. Rev.Ginecol.Obstet., v. 3, n. 2, p. 59-62, 1992.

04. BURROWS, R.A. et al. Variables psicossociales y familiares asociadas con el embarazo de adolescentes. Rev. Med. Chile, v. 122, n. 5, p. 510-6, 1994.
05. CARCELEN, M.T.; SOUZA, R.M. Gravidez na adolescência. In: CONGRESSO BRASILEIRO DE ENFERMAGEM, 47, 1995, Goiânia. Anais. Goiânia: Associação Brasileira de Enfermagem, 1995. p. 479-80.

06. COSTA, M,C.O.; PINHO, J.F.C.; MARTINS, S.J. Aspectos psicossociais e sexuais de gestantes adolescentes em Belém-Pará. J. Pediatr., v. 71, n. 3, p. 151-7, 1995.

07. COVA, M.A.C. Embarazo en la adolescencia. Rev. Cuba. Enferm., v. 9, n. 2, p. 117-31, 1993.

08. FREDIANI, A.M.; ROBERTO, C.M.; BALLESTER, D.A.P. Aspectos psicossociais da gestação na adolescência. Acta Med., v. 15, p. 349-60, 1994. 
09. GARCIA, T.R. Maternidade na adolescência: escolha ou fatalidade. Rev. Bras. Enfermagem, v. 45, n. 1, p. 44-53, 1992.

10. GILDEMEISTER, S.B. Prevenção da gravidez indesejada ou inoportuna. In: HALBE, H.W. Tratado de ginecologia. 2. ed. São Paulo: Rocca, 1993. p. 91-3.

11. GOMES, R. A análise de dados em pesquisa qualitativa. In: MINAYO, M.C.S.(Org). Pesquisa social: teoria, método e criatividade. Rio de Janeiro: Vozes, 1994. p. 67-80.

12. GRAVIDEZ em adolescentes. Consult. Med., v. 1, n. 1, p. 32, 1990.

13. GRIFFITHS, E.A. et al. Características psicosociales de la embarazada adolescente en Valdivia. Cuad. Med. Soc., v. 35, n. 2, p. 31-7, 1994.

14. HALBE, H.W. et al. A saúde da adolescente : ponto de vista ginecológico. In: HALBE, H. W. Tratado de ginecologia. 2. ed. São Paulo: Rocca, 1993. p. 76-80.

15. HALBE, H.W.; SANTANA, T.G.M. O estado e a atenção integral à saúde da mulher. In: HALBE, H. W. Tratado de ginecologia. 2. ed. São Paulo: Rocca, 1993. p. 58-68.
16. LOPES, G.P. Psicossomática da adolescência. Rev.Bras.Med.Ginecol.Obstet., v. 8, n. 2, p. 823, 1997.

17. LÜDKE, M.; ANDRÉ, M.E.D.A. Pesquisa em educação: abordagens qualitativas. São Paulo: EPU, 1986.

18. MARTINEZ, J. et al. Programa assistencial para la madre adolescente (Proama). Rev. Hosp.Matern. Infant. Ramon Sarda, v. 11, n. 2, p. 7-23, 1992.

19. ORGANIZAÇÃO MUNDIAL DE SAÚDE. La salud de los jóvenes: un reto y una esperanza. OMS: Genebra, 1995. 120p.

20. PINTO, L.F.M. Televisão e educação sexual. J. Pediatr., v. 71, n. 5, p. 248-54, 1995.

21. PINTO, R.P.; AZEVEDO, C.M. A gravidez na adolescência na perspectiva dos profissionais de saúde. In: BARROSO, C. et al. Gravidez na adolescência. Brasília: Iplan/Ipea, 1986. p. 5582.

22. VIÇOSA, G. et al. Programa de assistência integral à gestante adolescente (Paiga). Rev. Cient. Matern. Infant. Ginecol., v. 11, n. 1, p. 20-5, 1992.

23. ZIEGEL, E.E.; CRANLEY, M.S. Enfermagem obstétrica. 8. ed. Rio de Janeiro: Guanabara, 1985. p. 7-28. 